\title{
História local e fontes orais: uma reflexão sobre saberes e práticas de ensino de História
}

\author{
Selva Guimarães Fonseca*
}

Tradicionalmente, as séries iniciais do ensino fundamental na educação escolar brasileira constituíram, em primeira mão, um lugar privilegiado para a difusão de uma dada memória, uma história marcada por preconceitos, estereótipos e mitos políticos conservadores. As intenções das elites políticas dominantes, controladoras da difusão do conhecimento oficial, nos períodos ditatoriais no Brasil, eram explícitas nos currículos e materiais educativos. Nos primeiros anos de escolaridade, dever-se-ia desenvolver nos alunos determinadas noções e atitudes visando "ajustá-los", "integrá-los" à realidade social e histórica, tendo em vista que grande parte da população estudantil brasileira não ultrapassava os limites da $5^{a}$ série do ensino fundamental (então denominados ensino primário e depois ensino de $1^{\circ}$ grau). A disciplina "Estudos Sociais" cumpriu esta função em grande parte da história da educação brasileira, na segunda metade do século XX. Além disso, os argumentos locais e regionais eram e são, muitas vezes, usados como forma de mascarar os conflitos e contradições presentes na sociedade.

Essa perspectiva de ensinar História já não é mais a mesma. Os objetivos, as finalidades educativas, os currículos prescritos, os livros didáticos e a formação do professor se modificaram. Estamos vivenciando, desde as últimas décadas do século XX, um movimento de se repensar a História, as metodologias e as práticas de ensino. Entretanto, quando se

Professora do Programa de Pós-Graduação em Educação da Faculdade de Educação da Universidade Federal de Uberlândia. 
tratam das questões relativas à história local e às relações do local com o global, muitas dificuldades, dúvidas e problemas permanecem. Em tempos de globalização, por exemplo, o que significa falar em identidades locais, regionais e mesmo da identidade nacional? O que é ser mineiro, gaúcho ou nordestino no nosso País uno, diverso e plural? Como focalizar as questões locais por meio das fontes orais? Como o ensino de História na educação básica tem tratado esta problemática? O objetivo deste texto é identificar e analisar dificuldades, problemas relacionados ao ensino de história local nas séries iniciais; caracterizar experiências pedagógicas, e analisar possibilidades, propostas de ensino que abordam a história local e fontes orais.

Viajando por este Brasil, aonde quer que um mineiro, ou um gaúcho, um nordestino, um baiano vá, para além das fronteiras de sua região, depara-se com algumas construções imaginárias que preconceituam suas identidades. Fernando Sabino, depois de muito ouvir falar sobre mineiridade e mineirismos, sintetiza o que é ser mineiro por este Brasil afora:

É esperar pela cor da fumaça. É dormir no chão para não cair da cama. É plantar verde para colher maduro. É não meter a mão em cumbuca. Não dar passo maior que as pernas. Não amarrar cachorro com lingüiça. Por que mineiro não prega prego sem estopa. Não dá ponto sem nó. Mineiro não perde o trem. Mas compra bonde. Compra e vende para paulista. (Revista Veja Minas Gerais. Ano 24, n. 17, 24/04/91, p.11)

Os paulistas, por sua vez, retrucam a última definição de Sabino e dizem: "Mineiros são baianos cansados, que vinham do Nordeste e não conseguiram chegar até São Paulo" (ditado popular). Aqui, encontramos a imagem unificadora dos nordestinos que se deslocam para o sul: são todos "baianos" para os paulistas, ou "paraíbas" no Rio de Janeiro. À primeira vista, isto pode parecer "conversa mole" de brasileiro. Entretanto, como nos disse o poeta Drummond, "Minas não é uma só, Minas são muitas". Observamos que estas "conversas", "disputas", "casos", "piadas" estão presentes no nosso cotidiano e fazem parte do processo de construção e reconstrução da nossa identidade - que é plural -, da memória coletiva deste País. Nesse processo podemos refletir sobre as experiências vividas no passado e no presente, no local, na região, no País; 
podemos organizá-las, registrá-las, reconstruí-las, de forma que elas não se percam e passem a fazer parte da nossa cultura, das nossas tradições.

Nas práticas de ensino de História, as pesquisas têm nos revelado uma diversidade de maneiras de abordar os temas, de linguagens, fontes e materiais incorporados ao trabalho docente. Nós, professores, não apenas estamos na história, mas fazemos, aprendemos e ensinamos História. A educação histórica e a formação da consciência histórica dos sujeitos não ocorrem apenas na escola, mas em diversos lugares. Isto requer de nós uma relação viva e ativa com o tempo e o espaço do mundo no qual vivemos, por menor que ele seja. $\mathrm{O}$ meio no qual vivemos traz as marcas do presente e de tempos passados. Nele encontramos vestígios, monumentos, objetos, imagens de grande valor para a compreensão do imediato, do próximo e do distante. O local e o cotidiano como locais de memória são constitutivos, ricos de possibilidades educativas, formativas.

De acordo com Samuel (1989, p. 220):

A história local requer um tipo de conhecimento diferente daquele focalizado no alto nível de desenvolvimento nacional e dá ao pesquisador uma idéia muito mais imediata do passado. Ele a encontra dobrando a esquina e descendo a rua. Ele pode ouvir os seus ecos no mercado, ler o seu grafite nas paredes, seguir suas pegadas nos campos.

Essa afirmação nos conduz, necessariamente, a uma série de questionamentos que podem ser sintetizados na seguinte pergunta: se a história pode ser encontrada, ouvida, lida nos muros, nas ruas, nos quintais, nas esquinas, nos campos, como a educação básica tem tratado esta problemática? Isto nos leva a repensar as relações entre produção e difusão de saberes históricos; entre currículos prescritos e vividos, construídos no cotidiano escolar; entre memória, história e identidade; entre local e global.

Segundo Zamboni (1993, p. 7), em artigo publicado nos início dos anos de 1990, sobre o papel do ensino de História na construção da identidade:

O objetivo fundamental da História, no ensino de primeiro grau (ensino fundamental), é situar o aluno no momento histórico em que vive. [...] O processo de construção da história da vida dos alunos, de suas relações sociais, situados em contextos mais amplos, 
contribui para situá-lo historicamente, em sua formação intelectual e social, a fim de que seu crescimento social e afetivo desenvolva-lhe o sentido de pertencer.

Os Parâmetros Curriculares Nacionais (PCN's) de História do Ministério da Educação reforçam esta preocupação:

[...] o ensino e a aprendizagem de História estão voltados, inicialmente, para atividades em que os alunos possam compreender as semelhanças e as diferenças, as permanências e as transformações no modo de vida social, cultural e econômico de sua localidade, no presente e no passado, mediante a leitura de diferentes obras humanas. (Brasil, MEC, 1997, p. 49)

Apesar dos consensos construídos acerca da importância da problematização e do estudo do local para a formação histórica de crianças e jovens, é possível deparar, no cotidiano escolar, com uma série de dificuldades para a concretização destes objetivos. Em pesquisas por nós realizadas sobre o processo de ensino de História nas séries iniciais, foi possível constatar algumas características marcantes que evidenciam dificuldades recorrentes:

- a fragmentação rígida dos espaços e tempos estudados não possibilita que os alunos estabeleçam relações entre os vários níveis e dimensões históricas do tema. O bairro, a cidade, o Estado são vistos, muitas vezes, como unidades estanques, dissociados do resto do País ou do mundo;

- a naturalização e ideologização da vida social e política da localidade. O homem aparece como elemento da população ou membro de uma comunidade abstrata. O conceito de comunidade, por exemplo, é amplamente utilizado, de forma que pode servir para mascarar a divisão social, a luta de classes e as relações de poder, dominação e resistências que permeiam os grupos locais;

- o espaço reservado ao estudo dos chamados aspectos políticos. Ressaltam-se, por exemplo, temas recorrentes, nos currículos oficiais de alguns municípios: "a origem e a evolução do município e do Estado", "os vultos, pessoas que contribuíram para o progresso da cidade, da região". Nesta perspectiva, o bairro, o município, o Estado ou a região têm um destino linear, evolutivo pautado pela lógica dos vultos, de heróis, figuras 
políticas, pertencentes às elites locais ou regionais, que "fizeram o progresso" da região;

- as fontes de estudo, os documentos disponíveis aos professores, em geral, são constituídos de dados, textos, encartes, materiais produzidos pelas prefeituras, órgãos administrativos locais, com o objetivo implícito ou explicito de difundir a imagem de grupos detentores do poder político ou econômico. Assim, professores e alunos, muitas vezes, têm como fontes de estudo, evidências que visam à preservação da memória de grupos da elite local (Fonseca, 1992, 2003).

As dificuldades no tratamento da história local e regional são também recorrentes na pesquisa. Apesar das tentativas, dos esforços e das novas produções, é possível ainda afirmar que a história local continua "circunscrita a um grupo de entusiastas" e, "embora escrita como um trabalho de amor, é repetitiva e sem vida" (Samuel, 1989, p. 222). Segundo o autor, isso se deve à natureza dos documentos, que variam pouco de um lugar para outro e, em geral, registram atos dos governos locais, o que ele denomina por "tendência administrativa dos documentos". Uma outra dificuldade apontada pelo autor é a própria noção de história local como uma entidade distinta e separada, fenômeno único, como um conjunto cultural específico e periodização própria.

Se, reconhecidamente, as pesquisas educacionais, historiográficas e as práticas pedagógicas indicam a necessidade de novas configurações do ensino e aprendizagem da história local, como as diretrizes oficiais e os materiais didáticos têm tratado a temática? Em busca de respostas a estas questões recorremos ao texto da Lei de Diretrizes e Bases da Educação Nacional (LDB), de 1996; ao texto dos Parâmetros Curriculares Nacionais de História (PCN's), de 1997 e ao Guia do Livro Didático - 2007, produzido e divulgado pelo MEC no ano 2006.

A Lei de Diretrizes e Bases da Educação Nacional, de 1996, explicita o que o Estado brasileiro considera necessário transmitir aos alunos nas aulas de História: "Art. 26 \ $4^{\circ}$. O ensino de História do Brasil levará em conta as contribuições das diferentes etnias para a formação do povo brasileiro, especialmente das matrizes indígena, africana e européia”.

O texto dos Parâmetros Curriculares Nacionais, publicados pelo Ministério da Educação e Cultura em 1997, reafirma a importância do ensino de História desde os primeiros anos de escolaridade. Assim, alguns dos objetivos gerais do ensino de História traçados neste documento são: 
- identificar o próprio grupo de convívio e as relações que estabelecem com outros tempos e espaços;

- reconhecer mudanças e permanências nas vivências humanas, presentes na sua realidade e em outras comunidades, próximas ou distantes, no tempo e no espaço;

- questionar sua realidade, identificando alguns de seus problemas e refletindo sobre algumas de suas possíveis soluções. (Brasil, MEC, 1997, p. 41).

O mesmo documento reafirma que "a disciplina pode dar uma contribuição específica ao desenvolvimento dos alunos como sujeitos conscientes, capazes de entender a História como conhecimento, como experiência e prática de cidadania”. (Idem, p. 30).

Em relação aos currículos, os PCN's de História (1997) sugerem como conteúdos de História para o primeiro ciclo (duas primeiras séries do ensino fundamental) os seguintes temas: "História local e do cotidiano, a Localidade e Comunidade Indígena”. Para o segundo ciclo $\left(3^{\mathrm{a}}\right.$ e $4^{\mathrm{a}}$ séries) são propostos: "História das organizações populacionais, deslocamentos populacionais; organizações e lutas de grupos sociais e étnicos; organizações políticas e administrações urbanas; organização histórica e temporal". Os objetivos gerais e as temáticas selecionadas priorizam questões que partem do meio próximo da criança, dos espaços e grupos de vivência, da localidade, em diferentes temporalidades.

Em relação aos livros didáticos, o Guia do Livro Didático - 2007 (História séries/anos iniciais do ensino fundamental), que apresenta a avaliação das obras inscritas no Programa Nacional do Livro Didático (PNLD), realizada pela Comissão Técnica de Avaliação do MEC no ano 2006, afirma que, no conjunto das 27 obras avaliadas, nos chamados "livros regionais" - ou livros de História que têm como "recorte espacial uma capital (cidade) ou um Estado do País" - predominam os conteúdos com ênfase política e administrativa (Brasil, MEC, 2006, p. 22).

Segundo os avaliadores dos livros didáticos:

Em geral o que observamos em relação aos livros didáticos regionais é que a sua maioria não incorpora as renovações na área da História e da Pedagogia, escrevendo uma história relacionada paralelamente à História do Brasil. Quando trabalham assim em toda a obra, quase sempre destinam um capítulo, ou um encarte com muitas páginas para a história político-administrativa, quan- 
do não para temas da antiga disciplina Estudos Sociais, como símbolos nacionais, personagens ilustres e elementos do folclore local. (Brasil, MEC, 2006, p. 23)

O texto ressalta, entretanto, que há sinais de renovação em algumas obras analisadas. As conclusões desse documento evidenciam dificuldades dos autores de livros didáticos no tratamento da questão, conforme apontado por Samuel. Por outro lado, como bem sabemos, o que o professor ensina ou deixa de ensinar, o que o aluno aprende ou deixa de aprender, transcendem os limites das propostas curriculares, dos materiais didáticos que são elaborados a partir das diretrizes legais, demandas e critérios localizados fora da escola: órgãos do Estado, universidades, editoras e meios de comunicação. Isto requer de nós pensarmos sobre as mediações entre conhecimento histórico, alunos, professores, as mudanças sociais e culturais, o impacto das novas tecnologias na produção de novas informações, de novos conhecimentos e a construção de novas identidades coletivas.

Para Manique e Proença (1994, p. 24):

Uma identidade constrói-se a partir do conhecimento da forma como os grupos sociais de pertença viveram e se organizaram no passado, mas também da verificação da forma como se estruturam para fazer face aos problemas do presente, tendo uma componente que aponta para o futuro, pelo modo como este se prepara através da fixação de objetivos comuns.

Neste sentido, os autores portugueses defendem uma proposta a qual denominam de pedagogia da memória. Segundo eles:

Uma pedagogia da memória será, nestes termos, uma pedagogia da pluralidade e da diferença de tempos e culturas que, concomitantemente, promoverá uma nova relação do aluno com a duração e uma nova tolerância face ao outro, que tão arredia tem andado da historiografia escolar tradicional. Uma pedagogia da memória pressupõe ainda uma pedagogia do sujeito, o que, em termos didáticos, se traduz na adoção de estratégias implicativas inerentes a qualquer aprendizagem que se pretenda ativa. Numa 
pedagogia que tenha em conta a pluralidade de tempos e culturas, ocupam lugar privilegiado os estudos de história local. (Manique e Proença, 1994, p. 28)

Travería (2005, p. 19), ao analisar a questão da globalização e identidades nos currículos de História na atual realidade européia, particularmente da Espanha, aponta alguns desafios da educação obrigatória e do ensino de História no contexto de produção de novas identidades e novas relações de pertencimento: "viver a diversidade como uma riqueza, não como uma ameaça; ativar mecanismos de identificação e conhecimento do meio próximo ou entorno; construir identidades sociais abertas, não excludentes, capazes de dialogar com as demais, tornando possível integrar diversas identidades".

Se estabelecermos relação entre a proposta de estudo de história local dos PCN's e as preocupações dos autores supramencionados, encontraremos várias conexões, entrecruzamentos e aproximações. Concordamos com aqueles que defendem os estudos de história local na educação básica obrigatória. Do ponto de vista de uma proposta pedagógica, podemos construir uma "pedagogia de memória" que faça frente aos problemas de identidade, pertencimento, pluralidade cultural, étnica e religiosa e exclusão social que marcam as nossas escolas. Nesse sentido, a história local pode ter um papel decisivo na construção de memórias que se poderão inscrever no tempo longo, médio ou curto, favorecendo uma melhor relação dos alunos com a multiplicidade da duração.

O local e o cotidiano da criança e do jovem constituem e são constitutivos de importantes dimensões do viver; logo podem ser problematizados, tematizados e explorados no dia-a-dia da sala de aula, com criatividade, a partir de diferentes situações, fontes e linguagens. Assim, o ensinar e o aprender História não são algo externo, a ser proposto e difundido com uma metodologia específica, mas sim a ser construíd0 no diálogo, na experiência cotidiana em um trabalho que valorize a diversidade e a complexidade, de forma ativa e crítica. A memória das pessoas, da localidade, dos trabalhos, das profissões, das festas, dos costumes, da cultura, das práticas políticas, está viva entre nós. Nós, professores, temos o papel de, juntos com os alunos, auscultarmos o pulsar da comunidade, registrá-lo, produzir reflexões e transmiti-lo a outros. A escola e as aulas de História são lugares de memória, da história recente, imediata e distante. 
Sobre isto, Finocchio (2007), ao tratar a questão do ensino da história recente nas escolas argentinas, questiona sobre os aportes do ensino para a construção de identidades abertas e plurais, para o fortalecimento da democracia. ${ }^{1}$ Partindo do pressuposto que história e memória se misturam especialmente nas escolas, a autora analisa três lugares importantes para a reflexão sobre a história recente daquele país: a Plaza de Mayo, a obra Nunca Más e o filme La noche de los lápices, de Héctor Olivera (1986). Uma das conclusões da autora ao final do estudo é a seguinte:

Fica a impressão de que a história recente que a escola transmite às jovens gerações tem uma textura frágil, mais frágil que a que transferem outras instituições sociais, como os meios de comunicação, por exemplo. Fica a impressão, também, de que a escola é um espaço aonde chega a história, porém é, além disso (ou talvez mais) uma máquina imponente de memória institucionalizada. (Finocchio, 2007, p. 274)

Se os estudos do local são relevantes no processo de construção das identidades; ${ }^{2}$ se esse processo, na educação escolar, deve pautar-se na realidade em que vivemos, ou seja, numa sociedade marcada pela pluralidade étnica, religiosa, cultural e, também, por profundas desigualdades sociais e econômicas, como fugir às armadilhas, em especial àquelas que insistem em impor, no processo educativo nas escolas, uma memória das elites dominantes locais e nacionais? Como não permitir que a escola seja, como denomina Finocchio, "uma máquina imponente de memória institucionalizada"? Qual será o sentido da transmissão de uma memória local articulada à nacional, nas escolas, onde coexistem culturas e grupos tão diferentes?

Uma das dificuldades no estudo da história local, como já foi mencionada, é a excessiva fragmentação dos espaços, tempos e problemas que acaba dificultando a compreensão dos alunos. Neste sentido, cabem algumas considerações, buscando "fugir às armadilhas". A nosso ver, a fragmentação entre o local, o regional, o nacional e até mesmo o universal pode

1 As relações entre "história oral e tempo presente" são abordadas por Ferreira, 1996.

2 Sobre a categoria de identidade partilhamos das abordagens de Hall (2004) e de Bauman (2005). 
ser evitada na medida em que vários temas possibilitam a análise de diversos níveis e dimensões da realidade: o econômico, o social, o político e o cultural. É possível, por exemplo, trabalhar a singularidade e universalidade dos problemas sociais de nossas cidades quando comparamos um bairro de periferia das grandes cidades mineiras com um bairro das cidades de outros países da América, Ásia ou África.

O trabalho pedagógico em sala de aula pode contribuir para melhor inserção dos alunos na comunidade, identificando seus problemas, suas características, as mudanças e permanências do local, a construção da identidade, da cultura, a participação dos sujeitos, suas inserções e relações com o Brasil e o Mundo. Por exemplo, ao estudar as migrações internas no território brasileiro e a imigração, professores e alunos são motivados à compreensão dos deslocamentos de diferentes lugares do País e mundo. Assim, torna-se um trabalho de compreensão da formação da identidade plural do lugar onde vivem. A história deixa de ser única e homogênea, deixa de privilegiar as vozes dominantes a favor da multiplicidade de outras vozes e sujeitos históricos que construíram e constroem a história local.

Um aspecto relevante, no trabalho pedagógico de sala de aula, é reconhecer e considerar, na sociedade globalizada em que vivemos, o alto padrão de desenvolvimento das tecnologias dos meios de comunicação e transportes. A televisão, o rádio, a internet, os jornais, os demais meios de comunicação de massa e os meios de transportes redimensionaram nossas relações de espaço e tempo. A velocidade da circulação e do deslocamento de pessoas, mercadorias e informações faz com que, por exemplo, os alunos que vivem nos lugares mais afastados dos grandes centros urbanos tenham acesso a fatos distantes ao mesmo tempo, ou após um curto espaço de tempo, em que foram produzidos.

Autores de diferentes áreas do conhecimento têm abordado as relações entre o local e o global. Segundo Harvey, há na contemporaneidade, no debate político, uma saliência do nexo "local/global"; um verdadeiro fascínio por estudos em variadas disciplinas, obras que tratam dos "conhecimentos locais", das "culturas locais", da "construção do lugar". Entretanto, o autor adverte para o fato de que "seria um erro flagrante confundir o global de globalização com reivindicações mais gerais de universalidade (de verdades, preceitos morais, de ética ou de direitos)". Mas, também conforme o autor, "seria errôneo desprezar a ligação deveras 
robusta entre esses aspectos". A consideração conjunta do global e do local é vista, por ele, como "condição necessária (embora não suficiente) de criação de alternativas políticas e econômicas" (Harvey, 2004, p. 118-9).

Samuel (1989, p. 229) nos sugere que "ao invés de considerar a localidade por si mesma como objeto de pesquisa, o professor poderá escolher como ponto de partida algum elemento da vida que seja, por si só, limitado tanto em tempo como em espaço, mas usado como uma janela para o mundo".

Para Romero (apud Schmidt e Cainelli, 2004, p.116), "freqüentemente, coloca-se uma oposição entre ensinar a história local, a nacional e a história universal. Essa discussão nos parece inútil. A contraposição entre o local e o universal, o próximo e o longínquo, parece-nos falsa do ponto de vista científico e contraproducente em termos dos objetivos educacionais propostos. Nosso objetivo como docentes que têm a intenção de formar cidadãos de nossa nação e pessoas capazes de entender o mundo em que vivem, deveria fazer com que todos compreendessem o processo da História do nosso País, incluindo os três marcos sucessivos que lhe dão sentido: o latino-americano, o ocidental e o universal. Essa afirmação reconhece que o centro de preocupação deve estar na compreensão de nossa própria realidade, na medida em que esta realidade - recortada nos marcos do Estado e da nação - não é compreensível em si mesma".

Percebe-se que as propostas pedagógicas que privilegiam os estudos do local e do cotidiano, no processo de ensinar e aprender a pensar historicamente, caminham no sentido de romper com as dicotomias, a fragmentação, a separação entre espaços, tempos e sujeitos. O professor pode incorporar variadas fontes escritas e orais que permitem realizar trabalhos educativos, sem perder de vista os diversos aspectos da realidade histórica. Logo, são muito importantes o trabalho de seleção de fontes, as escolhas das linguagens, das estratégias e as metodologias usadas em sala de aula. Precisamos ter clareza de que tanto as fontes orais e documentos dos arquivos locais, como a literatura infanto-juvenil e canções, por exemplo, requerem, sempre, uma atitude ativa e crítica de professores e alunos. Destacaremos o trabalho com fontes orais.

Segundo Samuel (1989, p. 237-9):

A história local não se escreve por si mesma, mas como qualquer outro tipo de projeto histórico, depende da natureza da evidência 
e do modo como é lida. Tudo pode variar, desde a escolha do tema até o conteúdo dos parágrafos individuais. [...] O valor dos testemunhos depende do que o historiador lhe traz, assim como aquilo que ele leva, da precisão das perguntas e do contexto mais extenso de conhecimento e entendimento do qual elas derivam. O relato vivo do passado deve ser tratado com respeito, mas também com crítica; como o morto.

Quanto às fontes orais o autor defende:

[...] as entrevistas como formas capazes de fazer com que os estudos de história local escapem das falhas dos documentos, uma vez que a fonte oral é capaz de ampliar a compreensão do contexto, de revelar os silêncios e as omissões da documentação escrita, de produzir outras evidências, captar, registrar e preservar a memória viva. A incorporação das fontes orais possibilita despertar a curiosidade do aluno e do professor, acrescentar perspectivas diferentes, trazer à tona o "pulso da vida cotidiana, registrar os tremores mais raros dos eventos, acompanhar o ciclo das estações e mapear as rotinas semanais". (Samuel, 1989, p. 233)

Para Schwarzstein (2001, p. 40):

A história local é um aspecto importante, ainda que limitado do trabalho escolar com fontes orais. Pode-se partir do entorno para promover o interesse por problemas que o transcendem. Entretanto, é importante abordar o local, enfatizando a necessidade de colocá-lo em um contexto global, que permita a análise de um conjunto de relações. Dessa maneira, aproveita-se para a aprendizagem, simultaneamente, a atração ao concreto e próximo, e ao distante e diverso. O conjunto de desafios e possibilidades que analisamos com anterioridade tem conseqüências muito importantes no desenvolvimento atitudinal e nos instrumentos de aprendizagem que os alunos vão adquirindo através de sua prática, que aponta nessa direção. Assim, as exigências de desenhar um projeto, tarefa conjunta dos docentes com os alunos, eleger os entrevistados, elaborar os questionários e realizar as entrevistas, desenvolvem 
neles uma grande habilidade para formular perguntas, bem como um sentido crítico fundamental. Devem, ainda, desenvolver critérios de seleção de conteúdos, idéias principais, enfoques etc. $\mathrm{O}$ trabalhar com testemunhas que dão prova de maneiras diferentes de processar e avaliar os fatos do passado ajuda aos alunos a levar em consideração as múltiplas perspectivas dos diversos atores envolvidos.

Compartilhamos as idéias defendidas pelos autores sobre as possibilidades das fontes orais no trabalho pedagógico. ${ }^{3} \mathrm{~A}$ nosso ver, os projetos de história oral na educação básica pressupõem uma concepção de ensino de História que envolva a investigação, a pesquisa, a produção de saberes. O professor desempenha o papel de coordenador, o gestor das ações educativas, o mediador capaz de repensar, religar pesquisa e ensino, saberes e práticas.

O trabalho investigativo e interdisciplinar, a partir do cotidiano da criança e do jovem, por meio de fontes orais, ganha novas dimensões, na medida em que possibilita a problematização e a reflexão sobre a realidade que o cerca. Os alunos são motivados a levantar os testemunhos vivos, as evidências orais da história do lugar, buscando explicações: por que esta situação é assim? Por que isto mudou e aquilo permaneceu? As interrogações sobre o local em que vivem podem levar à busca de sentido, à compreensão do próximo e do distante, no espaço e no tempo. A História tem o papel de auxiliar o aluno na busca de sentidos para as construções e reconstruções históricas. Espaço e tempo não são duas categorias abstratas, mas preenchidas de historicidade.

Um exemplo de projeto de trabalho de história oral foi apresentado e desenvolvido, sob nossa orientação, no curso de Formação Superior de Professores - Veredas - no ano de 2005, com professores e alunos de $3^{a}$ e $4^{a}$ séries do ensino fundamental, na rede pública do Estado de Minas Gerais. O projeto interdisciplinar, envolvendo as disciplinas História, Geografia, Língua Portuguesa e Matemática, teve como objetivos "caracterizar e analisar a diversidade étnica e cultural da população brasileira", bem como "analisar e comparar as condições sociais e econômicas da

3 A obra Manual de História Oral (Meihy, 2002) constitui importante fonte para a elaboração de projetos de ensino de História para o ensino fundamental e médio. 
população brasileira no passado e no presente" (Fonseca e Guimarães, 2005, p.133-4). O projeto foi construído da seguinte forma:

a) problematização do tema;

b) planejamento do estudo;

c) desenvolvimento do trabalho - etapa em que foi projetado e desenvolvido um elenco de atividades investigativas;

d) síntese e avaliação.

A primeira atividade consistiu na elaboração, preparação e realização de entrevistas orais com familiares dos alunos, com o objetivo de mapear os lugares, as regiões de origem das famílias dos alunos, os deslocamentos, os movimentos migratórios, os motivos da escolha ou da não escolha do lugar para viver. Também foram reconstruídas as histórias das famílias, dos sobrenomes, os hábitos alimentares, costumes, religiões e outras características socioculturais dos grupos familiares. As entrevistas orais possibilitaram a compreensão da pluralidade da população, a convivência de pessoas de diversas regiões com hábitos, valores, culturas diferentes, o compartilhamento de problemas, o diálogo sobre as diferenças e semelhanças de modos de ser e viver. Os registros foram complementados com indicadores sociais e populacionais do Instituto Brasileiro de Geografia e Estatística (IBGE) e Instituto de Pesquisas Aplicadas (IPEA); dados do Ministério das Relações Exteriores sobre imigração e emigração e da Organização das Nações Unidas (ONU) sobre as condições de vida da população brasileira e de outros países. Além disso, foram utilizadas fontes como textos, mapas e canções. Ao final do projeto, alunos e professores das turmas foram motivados a produzir um pequeno livro ilustrado que recebeu o título $A$ gente faz um país. Este projeto foi desenvolvido de modo distinto, com variações em diversas escolas do Estado de Minas Gerais.

Os relatos dos professores, particularmente nos memoriais, demonstraram como as experiências com a história oral podem ser exitosas e gratificantes para os alunos. A investigação sobre quem somos nós, brasileiros, como vivemos, qual é nossa "cara", possibilita não só refletir sobre a nossa identidade, mas o diálogo entre identidades, de forma democrática e cidadã.

Assim, projetos de história oral, práticas educativas que possibilitam "fugir às armadilhas" requerem do professor uma relação crítica com as concepções de História, tradicionalmente dominantes, nos primeiros anos 
de escolarização. Trata-se de assumir uma postura dialética que lhe permita captar e representar, com nossos alunos, o movimento sócio-histórico e temporal das sociedades, as contradições, as especificidades, as particularidades, sem perder de vista a universalidade. A formação da consciência histórica, o respeito às tradições locais e orais pressupõem a compreensão do "eu" no "mundo", do "uni"-"verso", enquanto dinâmica, movimento, transformação, história!

No momento de conclusão, gostaríamos de reforçar que a nossa intenção é contribuir para o aprofundamento das reflexões sobre os saberes e as práticas pedagógicas desenvolvidas em sala de aula. Tivemos a intenção de identificar dificuldades, problemas relacionados ao ensino de história local nas séries/anos iniciais, ressaltando alguns consensos construídos a respeito da formação da identidade, do desenvolvimento das noções de espaço e tempo na criança, que constituem a base do ensino de História na escolarização. Apesar disso, muitas vezes, o estudo se processa de forma fragmentada e sem vida. Procuramos pensar sobre outras experiências pedagógicas e propostas de ensino de história local. Registramos as diretrizes propostas pela LDB/96 e os PCN's da área de História. Destacamos os objetivos e os temas relativos à história local e do cotidiano, sua importância, o papel e o significado para a formação da consciência histórica dos sujeitos. Em seguida, focalizamos a abordagem denominada pedagogia da memória como uma postura pedagógica fundada no respeito e compreensão da pluralidade, da diferença de tempos, espaços, culturas que proporciona a construção de novas relações, do aluno com outros sujeitos, tempos e espaços.

Buscamos analisar possibilidades de trabalho com história oral no ensino e na aprendizagem da História com a intenção de contribuir para a busca de respostas sobre como fugir às armadilhas e evitar a fragmentação no tratamento das questões locais. As alternativas apresentadas caminham no sentido de articular o local ao nacional, ao global, no contexto social e multicultural em que vivemos. Reafirmamos nossa defesa da história oral como possibilidade de diálogo passado e presente, de ouvir a voz do outro, de trabalho com memória individual e coletiva. Nesse sentido, reiteramos nossa posição relembrando as palavras de Bosi (1992, p. 28):

[...] a memória articula-se formalmente e duradouramente na vida social mediante a linguagem. Pela memória as pessoas que se au- 
sentaram fazem-se presentes. Com o passar das gerações e das estações esse processo "cai" no inconsciente lingüístico, reaflorando sempre que se faz uso da palavra que evoca e invoca. É a linguagem que permite conservar e reavivar a imagem que cada geração tem das anteriores. Memória e palavra, no fundo inseparáveis, é a condição de possibilidade do tempo reversível.

Memória e palavra, escola e história, lugares de produção de identidades, de formação, de educação. Mais do que difundir respostas para perguntas, oferecer soluções acabadas para os problemas, a história oral, na educação básica, nos permite penetrar, trocar, compreender e dialogar com o Outro.

\section{Referências bibliográficas}

BAUMAN, Z. Identidade. Rio de Janeiro: Zahar, 2005.

BRASIL. MEC. Parâmetros Curriculares Nacionais - História e Geografia. Brasília: MEC/SEF, 1997.

BRASIL. MEC. Secretaria de Educação Básica. Guia do Livro Didático 2007: História: séries/ anos do ensino fundamental. Brasília: MEC/SEB, 2006. (disponível no site www.mec.gov.br).

BOSI. A. O tempo e os tempos. In: NOVAES, Adauto (org.). Tempo e História. São Paulo: Cia. das Letras / Secretaria Municipal de Cultura, 1992.

HALL, S. A identidade cultural na pós-modernidade. Rio de Janeiro: DP\&A, 2004.

HARVEY, D. Espaços de esperança. São Paulo: Loyola: 2004.

FERREIRA, M. M. História oral e tempo presente. In: MEIHY, J.C.S.B. (org.). (Re)introduzindo História Oral no Brasil. São Paulo: Xamã, 1996, p.11-21.

FINOCCHIO, S. Entradas educativas en los lugares da memoria. In: FRANCO, M P.; LEVÍN, F. (comp.). Historia reciente: perspectivas y desafios para um campo en construcción. Buenos Aires: Paidós, 2007, p. 253-77.

FONSECA, S. G. O ensino de História e Geografia nas séries iniciais. Ensino em Re-Vista. Edufu, v. 1, n. 1, 1992.

FONSECA, S. G.; GUIMARÃES, I. V. A gente faz um país. In: SALGADO, M.U.C; MIRANDA, G.V. (org.). Veredas - Formação Superior de Professores: projetos de trabalho. Belo Horizonte: SEE/MG, 2005, v. 7, p. 131-46.

MANIQUE, A P.; PROENÇA, M.C. Didáctica da História: Património e História Local. Lisboa: Texto Editora, 1994. 
MEIHY, J.C.S B. Manual de História Oral. São Paulo: Loyola, 2002.

SAMUEL R. História local e história oral. Revista Brasileira de História. São Paulo, ANPUH, v. 9, n. 19, p. 219-242, 1989.

SCHWARZSTEIN, D. Uma introducción al uso de la bistoria oral en el aula. Buenos Aires: Fondo de Cultura Económica de Argentina, 2001.

SCHMIDT, M. A.; CAINELLI, M. Ensinar História. São Paulo: Scipione, 2004.

TRAVERÍA, G, T. Enseñar a pensar históricamente: los arquivos y las fuentes documentales en la enseñanza de la historia. Barcelona: ICE/Universitat de Barcelona/HORSORI, 2005.

ZAMBONI, E. O ensino de História e a construção da identidade. In: História. São Paulo: SEE/SP, 1993. Série Argumento.

Resumo: $\mathrm{O}$ artigo tem como objetivo analisar as dificuldades e problemas relacionados ao ensino de história local, buscando caracterizar experiências pedagógicas e propostas de ensino para a disciplina com a incorporação das fontes orais. A partir da literatura na área de investigação do ensino e aprendizagem de História e do trabalho com diferentes fontes e linguagens, o texto analisa diferentes possibilidades de trabalho com história local e fontes orais como estratégias de aprendizagem da História na educação básica. O texto tem como finalidade contribuir para o debate acerca dos saberes e práticas de ensino e história oral.

Palavras-chave: história local; história oral; ensino de História.

Local History and Oral Sources: a Reflection on Knowledge and Practices of History Teaching

Abstract: The article has as objective to analyze difficulties and problems related to the teaching of local history, trying to characterize pedagogical experiences and teaching proposals of local history; it also incorporates the oral sources. With the help of the literature in the area of investigation regarding the teaching and learning of History and the work with different sources and languages, the text analyzes different work possibilities with local history and oral sources as being learning strategies of History in the elementary level. The text has as purpose to contribute for the debate concerning knowledge and practices of teaching and oral history.

Keywords: local history; oral history; History teaching. 